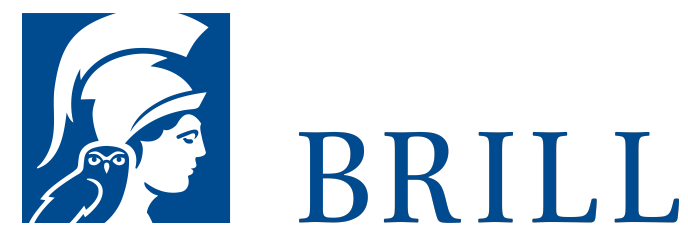

\title{
Einladung in die Philosophie
}

\section{Author: Franz von Kutschera}

Das Buch mÃ $\uparrow$ chte den Leser fã $1 / 4$ r die zentralen Fragen der Philosophie interessieren und ihm ein tieferes Verst Ãøndnis fÃ $1 / 4 \mathrm{r}$ ihre Ãœberlegungen vermitteln. Es setzt daher keine philosophischen Kenntnisse voraus, sondern nur die Bereitschaft und die FÃæahigkeit, ungewohnten und oft abstrakten GedankengÃăngen zu folgen. Die Fragen, die in diesem Buch erÃ $\llbracket$ rtert werden, geh $\tilde{\Upsilon}$ ren zu verschiedenen Gebieten der Philosophie, zur Erkenntnistheorie, Metaphysik, zur Philosophie des Geistes, der Sprache und der Mathematik, zurWissenschaftstheorie, praktischen Philosophie, Ã „sthetik und zur philosophischen Anthropologie. Doch es stellt diese Fragen nicht nur, sondern es gibt auch Antworten. Es ist aus der Ãœberzeugung geschrieben, dass sich oft Antworten auch auf sehr grundsÃatzliche philosophische Fragen finden lassen, sofern man sie nur klar formuliert und systematisch erÃ $\llbracket$ rtert. Der Leser ist aufgefordert, diese Antworten selbst kritisch zu Ã 1/4berdenken: Denn Philosophieren heiÃ Ÿt ja vor allem, selbst zu denken, und dazu lãadt dieses Buch ein.

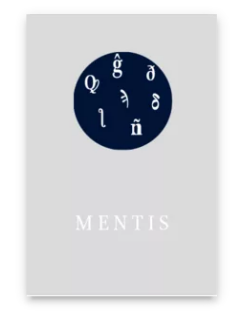

Published: 27

Mar 2018

Pages: 201

Seiten

Subjects:

General,

Philosophy

Publisher: Brill | mentis

E-Book (PDF)

ISBN: 978-3-

95743-871-3

Paperback

ISBN: 978-3-

95743-054-О

Price:

[USS.] Â \$42.00 
Please send your order to: Brockhaus/Commission Tel: +49(o)71 541327 9216 | E-Mail: brill@ $\underline{\text { brocom.de }}$

For questions please contact: Brill Deutschland GmbH

Wollmarktstraße 115 | 33098 Paderborn | Germany

Tel: +49 (o)5251 69975 o | E-Mail: sales@brill.com. 